\title{
Correction to: Existence and uniqueness of solution of a fractional order tuberculosis model
}

Isa Abdullahi Baba ${ }^{1, a}$ and Behzad Ghanbari ${ }^{2,3}$

1 Bayero University Kano, Kano, Nigeria

2 Department of Engineering Science, Kermanshah University of Technology, Kermanshah, Iran

3 Department of Mathematics, Faculty of Engineering and Natural Sciences, Bahcesehir University, 34349 Istanbul, Turkey

Original article: Eur. Phys. J. Plus (2019) 134: 489, https://doi.org/10.1140/epjp/i2019-13009-1

Received: 3 October 2019

Published online: 22 October 2019

(C) Società Italiana di Fisica / Springer-Verlag GmbH Germany, part of Springer Nature, 2019

After publication, the authors realized that institutes were not correctly given. Here is the correct version.

${ }^{a}$ e-mail: isababa7@yahoo.com (corresponding author) 